\title{
Cultivating of Service-Oriented Pharmaceutical Talents in China
}

\author{
Rong $\mathrm{Xu}^{1,2}$, Mingli Shao ${ }^{1 *}$ \\ ${ }^{1}$ School of International Pharmaceutical Business, China Pharmaceutical University, Nanjing, China \\ ${ }^{2}$ School of Pharmacy, Shanghai Jiaotong University, Shanghai, China \\ Email: xurong@sjtu.edu.cn
}

Received October $30^{\text {th }}, 2013$; revised November $30^{\text {th }}$, 2013; accepted December $7^{\text {th }}$, 2013

\begin{abstract}
Copyright (c) 2013 Rong Xu, Mingli Shao. This is an open access article distributed under the Creative Commons Attribution License, which permits unrestricted use, distribution, and reproduction in any medium, provided the original work is properly cited. In accordance of the Creative Commons Attribution License all Copyrights (C) 2013 are reserved for SCIRP and the owner of the intellectual property Rong Xu, Mingli Shao. All Copyright (c) 2013 are guarded by law and by SCIRP as a guardian.
\end{abstract}

\begin{abstract}
Health Care System Reform of China puts forward new requirements for service-oriented pharmaceutical talents. Traditional mode of higher pharmaceutical education in China could not meet the social demand because of its "drug-centered" teaching system and shortage of service-oriented pharmaceutical talents. So it is urgent to transform the traditional mode and cultivate application-oriented pharmaceutical talents. This paper will give some suggestions, including establishing uniform standards for cultivating service-oriented pharmaceutical talents and transiting traditional curriculum and teaching methods. Moreover, it is feasible to establish effective linkup between professional degree and license examination.
\end{abstract}

Keywords: Higher Pharmaceutical Education; Service-Oriented Pharmaceutical Talents; Pharmacy Professional Degree

\section{Introduction}

In March 2009, the CPC Central Committee and the State Council put forward Opinions of Deepening Health Care System Reform, and then issued Implementation Plan for the Recent Priorities of the Health Care System Reform (2009-2011). Such moves marked the official presence of New Healthcare Reform Scheme. In that new program, explicit requirements of pharmaceutical service have been proposed. For instance, pharmacists should supply the qualified drugs, standardize clinical use of drugs, ensure correct use of medicines and satisfactory service accessible to patients etc. Again in March 2012, the plan, Deepening Reform Planning and Implementation Scheme of Healthcare system during Twelfth Five-Year period, has set higher standards on pharmacy services and pharmacists training. In recent years, requirements of pharmacists are undergoing such changes as from being "drug-centered" to "patient-centered" from drug supply to pharmaceutical service and from drug management to service management. A stark contrast to these changes is that we are still short of service-oriented pharmaceutical talents in terms of both quantity and quality, which has been capping the further development of pharmacy due to traditional education mode. Therefore, it is urgent to transfer the mode of cultivating pharmaceutical talents in China.

\section{Main Problems and Challenges}

\section{Traditional Pharmacy Education: Drug-Centered Teaching System}

The aim of traditional pharmacy education system in Chinese pharmacy schools or universities is to cultivate research-oriented students. The curricula are designed to focus on technical

\footnotetext{
${ }^{*}$ Corresponding author.
}

knowledge of pharmacy and to teach principles and techniques of drug discovery and development. Through comprehensive studies, pharmacy students may obtain solid knowledge of laboratory procedures and scientific methods. Without doubt, this kind of education system has fostered a large number of researchers which greatly contributed to the development of pharmaceutical industry. According to the statistics on pharmacy graduates' (including TCM) employment from Chinese Pharmaceutical Yearbook 2009, half of them took marketing, manufacturing or research positions in pharmaceutical industry, $18 \%$ took teaching or research positions in academia, $1 \%$ worked in the administrative organs, while only $7 \%$ took dispensing positions in hospital pharmacies (Chen, 2012). Others continued their studies at a higher level or simply changed their professions. Obviously, China's traditional pharmacy education gives first priority to cultivate research-oriented talents.

\section{Acute Shortage of Service-Oriented Pharmaceutical Talents}

Nowadays, with the advancement of society and increasing demand for health care, service-oriented pharmaceutical talents mastering the knowledge of drug application become scarce in our society. In the meantime, plannings or programmings recently issued have formulated the minimum scale of serviceoriented pharmaceutical talents. For example, Pharmaceutical Affairs Management Regulation of Medical Institutions (2011) demands pharmacists with a quantity of no less than $8 \%$ of the hospital technical personnel. On this score, Chinese medical institutions will need approximately 610,000 pharmacists by 2020. At the same time, according to National Drug Safety Plan (2011-2015) which foresees one pharmacist for every drugstore, Chinese pharmaceutical retailers will need about 390,000 
pharmacists by 2020. In total, more than 100 million pharmacists are needed. Considering the current no more than 400,000 pharmacists, there seems a long way for the team construction of pharmaceutical talents.

\section{Unreasonable Positioning of Cultivating Pharmaceutical Talents}

As stated above, due to the unreasonable positioning for the overall cultivating of pharmaceutical talents, a big gap exists in China between the existing training model and market requirements. Under the guidance of traditional pharmacy education, obvious structural defects of knowledge occur in reality. For many students, shortage of biomedical knowledge and clinical practice skills lead to low proficiency in the selection and evaluation of clinical medicine treatment. The ignorance of a humanistic care of patients invites more attention to drug development, manufacture and marketing. Consequently, most of them were nothing but drug suppliers and felt difficulty in providing pharmaceutical service in face of patients (Wu, 2004). Obviously, such purely academic pharmacy education does not meet the demands of cultivating service and applica-tionoriented pharmaceutical talents.

\section{Current Situation}

\section{Trend of Cultivating Application-Oriented Talents in China}

In March 2009, the Ministry of Education of China proposed plans to increase the enrollment of full-time professional degree graduates and then issued criteria for the training scheme with an emphasis on teaching methods, practice teaching and so on. The initiative reflected a major change of development strategy of graduate education, shifting from academic education to application-oriented education at the post-graduate level. In January 2010, Master Program of Pharmacy Professional Degree was deliberated and finalized at the 27th meeting of the Academic Degrees Committee of the State Council. After four months, the specific scheme was issued (State Council Academic Degrees Committee, 2012). As one of the earliest established full-time professional degree programs at the postgraduate level, Master Program of Pharmacy Professional Degree will strengthen the way of cultivating application-oriented talents.

\section{Learning from Pharmacy Education in US}

Long-term professional education system is the trend of reform in International pharmacy education for the purpose of fostering reliable pharmacists. Advanced concept of pharmacy education in the United States has been well recognized and followed by many countries in the world. Academic degree and professional degree are two cultivation models co-existing in pharmacy education in U.S. and three different levels of postgraduate degrees are available: Master of Science (M.S.), Doctor of Philosophy (Ph.D.) and Doctor of Pharmacy (Pharm. D.). M.S. and Ph.D. belong to academic degrees, while Pharm. D. is the first professional degree (Jiang, Zhang, \& Yu, 2009). Students obtaining academic degree mainly engage in scientific research, whereas students applying for pharmacist licenses should obtain the degree of Pharm. D. In that sense, professional degree Pharm. D. proves to be a prerequisite for becoming a pharmacist.
In that way (as shown in Figure 1), pharmacy education system in the United States has clearly formed research-based academic route and application-based professional route. To meet the actual needs of the society, Pharm. D. graduates should also pass the qualification license of pharmacists. Furthermore, only Pharm. D. graduates are eligible to participate in this kind of qualification examination (Zhang JG \& Zhang ZG, 2008).

\section{Conclusion and Suggestion}

\section{Necessity and Feasibility of Developing Service-Riented Pharmaceutical Talents}

According to statistics from World Health Organization, 1/7 people died of irrational drug use instead of natural aging or diseases and 1/3 patients died of irrational drug use. In China, irrational drug users account for about $11 \%$ - $26 \%$ of total patients (Li \& Zhou, 2011). The incidence of severe drug- induced diseases like drug addiction, malformations, blindness, shock, kidney damage, and cell mutation reached up to $30 \%$. However, if pharmacists participate in a treatment program, the risk of irrational drug use could be effectively reduced. An investigation of clinical pharmacists intervention in clinical treatment for epilepsy surgery patients revealed that the average length of stay can be decreased by $23.2 \%$ and antibiotic usage by $47.2 \%$. At the same time, postoperative seizure control rate was reduced by $43.2 \%$ and the cost was also significantly reduced (Wu, Lv, \& Yan, 2009). It showed that pharmacists' intervention contributed a lot in minimizing the risk of improper use of medicines. In many countries, the proportion of pharmacist to the population has been an indicator measuring a country's public health level, especially pharmaceutical care level. The following table (see Table 1) shows the total amount of pharmacists and population density of pharmacists in some countries. Obviously, China has the lowest rate of population density of pharmacists owing to its large population base and deficient pharmacists. There is still a wide gap in this regard between China and other developed and developing countries (Wu, 2009).

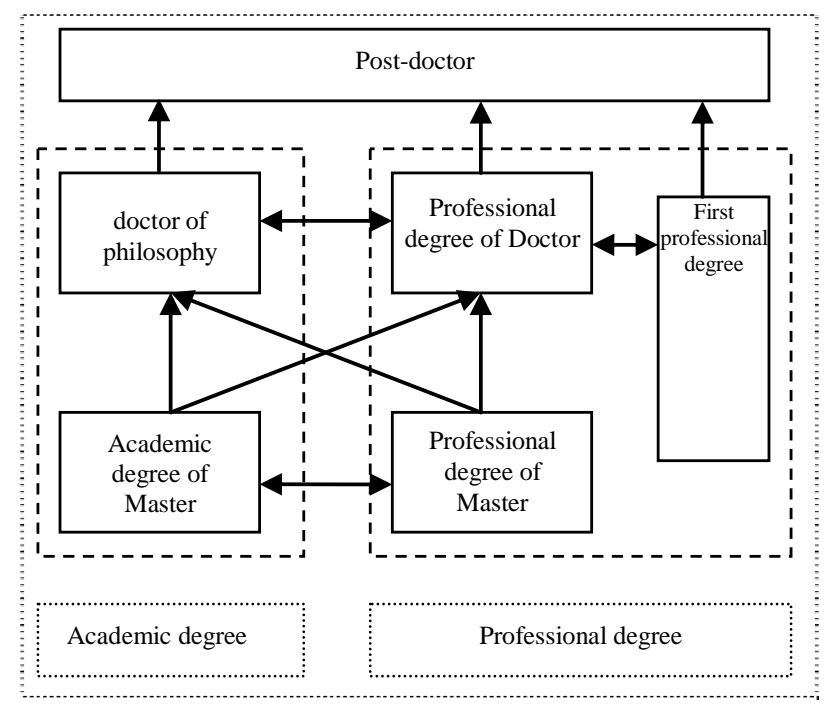

Figure 1.

Education system after undergraduate level in US Notes: the arrows indicate the possible transformational relation between degrees. 
Table 1.

Total amount of and population density of pharmacists in some countries (Statistics from WHO in 2010).

\begin{tabular}{ccc}
\hline nationality & $\begin{array}{c}\text { total amount of } \\
\text { pharmacists (thousands) }\end{array}$ & $\begin{array}{c}\text { population density of } \\
\text { pharmacists (per thousand) }\end{array}$ \\
\hline US & 249.642 & 91 \\
UK & 48.972 & 80 \\
Australia & - & 75 \\
Japan & - & 195 \\
Brazil & 104.098 & 60 \\
India & 592.577 & 61 \\
$\begin{array}{c}\text { China(exclude HK, } \\
\text { Macao and Taiwan } \\
\text { regions) }\end{array}$ & 382.240 & 30 \\
\hline
\end{tabular}

Encouragingly, the importance of training pharmacists, particularly clinical pharmacists, has been recognized in recent years in China. Some hospitals and colleges have commenced the cultivation about clinical pharmacy. Starting from investigating clinical medicines and analyzing prescription, the domestic clinical pharmacists participated in clinical drug therapy and gradually involved in clinical drug therapy like providing pharmaceutical information, monitoring therapeutic drug and adverse drug reaction as well as other clinical work.

Specialty of clinical pharmacy has been introduced in some schools. A variety of degrees are offered by various programs partially because there is no standardization of curricula. BS degrees in pharmacy or medicine, MS degrees in pharmacy or medicine, and $\mathrm{PhD}$ degrees in pharmacy can all have components of clinical pharmacy. Despite absence of unified standards and guidelines in pharmaceutical talents cultivation, in any case, those graduates have relieved the pressure of China's demand. Unfortunately, there are as few as 500 graduates each year which fails to satisfy the demand of a total of 30 thousands clinical pharmacists (Liu \& Chen, 2010).

Unified standards of pharmacy training should be established in order to cultivate high-level pharmacists. Long educational system of 6 - 7 years for combined Bachelor's/Master's Degree Program is recommended to acquire the pharmaceutical and medical knowledge as well as adequate practice time, which will improve students' ability to identify, analyze and solve practical problems. Pharm. D. degree has not been introduced to our country and Professional Master of Pharmacy (M. Pharm.) is recommended to be granted.

\section{Transition of Pharmacy Curricula and Teaching Methods}

Training for service-oriented pharmacy personnel should be positioned in professional education with the purpose of helping pharmacists render pharmaceutical services to patients during disease prevention and treatment. As a good pharmaceutical worker, besides extensive knowledge of medicine, effective communication with patients facilitating efficient pharmaceutical care is also a must. Therefore, several course modules with therapeutics as the core should be set up which includes biomedicine, pharmaceutical science, clinical science and social/ behavioral/management science. In particular, biomedicine module includes courses of anatomy, physiology, biochemistry, pathology and cell biology; pharmaceutical science module in- cludes medicinal chemistry, pharmacology, bio-pharmacy, drug pharmacokinetics, while toxicology and pharmacogenetics are offered by circumstance. Clinical science module includes pharmaceutical service for special population, drug information and literature evaluation, drug metrology, patient assessment, and pharmaceutical service skills. Social science courses like pharmaceutical administration, pharmaco economics, interpersonal communication, ethics and psychology constitutes the module of social/behavioral/management science. Besides taught courses, students should serve in hospital pharmaceutical for about one year for practice.Instructions of knowledge, practical skills, professional attitudes and values should run throughout the entire curricula and pharmacy practice.

In response to the transition of market demands, the abovementioned modes and flexible methods of education would be adjusted in time to fulfill the requirements for professional competence and transform pharmaceutical education into a professional and applied one with great practicality and adaptability.

\section{Establish Effective Linkup between Professional Degree and License Examination}

The orientation of developing Master of Pharmacy Professional Degree in exploration is to cultivate high-level pharmaceutical specialists with strong ability for technical innovation and problem-solving. Consequently, practice is the key to enhance this ability. In order to distinguish the training scheme of professional programs from academic ones, many colleges and universities only scale up practice in original scheme instead of renewing training specifications, which leaves professional programs no clear distinction with academic type but still follow the traditional mode of pharmacy education, and consequently fails to produce applied talents in need. On the other hand, burgeon of our licensed pharmacists is suffering bottlenecks of shortage both in quantity and in quality. The national licensed pharmacist registration statistics in first quarter of 2010 showed that registered licensed pharmacists with bachelor degree and three-year college education made up $73 \%$ of all enrollments, while pharmacists with secondary vocational school education merely accounted for $24 \%$ and rare with master degree or doctoral degree (State Food and Drug Administration licensed pharmacist Credentialing Center, 2010). The main reason for it is that high-level pharmaceutical professionals remain shortsupplied. Therefore, it is feasible to establish effective linkup between professional degree and license examination and further make professional degree a prerequisite to licensing. In doing so, social recognition of professional degree would be promoted and pressure in need of licensed pharmacists would be relieved once pharmacy degree training program accords with the requirements of licensed pharmacists. For better integration, the department in charge of Licensed Pharmacist Examination should associate with the pharmacy professional education to ensure quality of professional degree, via intervening in the applicants' qualification, training programs and other aspects of degree conferring, evaluation and quality control etc.

\section{REFERENCES}

Chen, Z. (2012). Actual needs should be the vane for pharmaceutical personnel training. China Pharmaceutical News, 8, 1-2.

Wu, C. F. (2004). Thinking about pharmacy service-oriented personnel 
training. Pharmaceutical Education, 20, 1-2.

State Council Academic Degrees Committee. (2012). Notice on issuing program of setting 19 Master's Degree in the field of Finance and so on. http://www.chinadegrees.cn/xwyyjsjyxx/bf/265402.shtml

Jiang, H., Zhang, Y. Z., \& Yu, B. Y. (2009). Establishing pharmacy professional degree in China, Pharmaceutical Education, 25, 1-4.

Zhang, J. G., \& Zhang, Z. G. (2008). Introduction and inspiration of degree structure of professional education in U.S. Higher Education Research, 29, 104-109.

Li, Z. Q., \& Zhou, H. P. (2011). Reasonable analysis of hospital medication, Journal of PLA Pharmaceutical, 27, 272-274.
Wu, Y. P., Lv, H. M., \& Yan, Q. (2009). Accelerating clinical pharmacist system to promote the establishment of the medical team, Chinese Hospital, 13, 2-5.

Wu, K. Y. (2009). Strategic research in construction of licensed pharmacists in China. Chinese Health Policy Research, 2, 36-41.

Liu, G. L., \& Chen, R. (2010). Status and role of the clinical pharmacist under the new situation of health care reform. Chinese Pharmacy, 21, 2785-2790.

2010 national registration of licensed pharmacist in the first quarter of statistics (2010). State Food and Drug Administration licensed pharmacist Credentialing Center, Beijing, 129. 